\title{
La publicación por parte de los centros de arbitraje de laudos que no hayan sido impugnados
}

Francisco Bustamante Luna*

Recibido/Received: 16/09/2021

Aceptado/Accepted: 17/10/2021

\begin{abstract}
Sumario: 1. Introducción. 2. La confidencialidad. 2.1. Distintas categorías de leyes y sistemas. 2.2. El caso de Ecuador. 2.3. La teoría de que la confidencialidad es inherente al arbitraje. 2.4. Extensión de la confidencialidad. 3. Normas de algunos países y centros de arbitraje sobre la publicidad de los laudos 4. Jurisprudencia internacional con relación a la publicidad de los laudos. 5. Razones a favor y en contra de la publicación de los laudos arbitrales. 6. Conclusiones.
\end{abstract}

Resumen: La publicación de los laudos arbitrales como medida de transparencia y herramienta para estudio de casos análogos, enfrenta a una corriente de defensores de la tesis de que la confidencialidad del proceso arbitral se extiende inclusive a los laudos arbitrales. Las legislaciones y centros de arbitraje, que aprecian y defienden el deseo de las partes de mantener la reserva en los asuntos materia de controversia, han actuado cautelosamente en cuanto a la posibilidad de publicidad. No han dejado de reconocer los argumentos a favor de esta y algunos centros arbitrales de prestigio han efectuado reformas a sus normas y reglamentos para regular con condicionamientos la mencionada publicidad. En general, se debe cumplir exigentes requisitos concretos para que esto ocurra. Este artículo busca dar algunos antecedentes y orientaciones, a fin de que en el Ecuador se encuentre un equilibrio en las medidas que deben tomar los centros para resolver el problema, robusteciendo el mecanismo arbitral a tono con los tiempos.

\footnotetext{
* Abogado y Doctor en Jurisprudencia por la Pontificia Universidad Católica del Ecuador.

Árbitro de los Tribunales de la Cámara de Comercio de Quito.
} 
Palabras Clave: Publicidad, publicación, confidencialidad, centros de arbitraje, laudos arbitrales.

\title{
Publication by arbitration centers of awards that have not been contested
}

\begin{abstract}
Third Party Funding (TPF) is a mechanism that has gained an important role in international arbitration since the last decade. Essentially, TPF means that a third party decides to finance one of the parties with all or part of the costs and expenses related to the arbitration process in exchange for an economic retribution. Although TPF is not new in Europe or the United States to grant access to justice, in Latin American it has gained popularity in recent years. In Ecuador, this mechanism is still novel for many. Furthermore, the Arbitration and Mediation Law does not make any reference to TPF or the obligations of the parties that receive financing. However, with the increase of arbitrations in which one of the parties is being financed, it is worth asking: Do the parties have the obligation to disclose this situation to the arbitrators? Is there a legal obligation of disclosure under Ecuadorian Law? This article explores the figure of TPF in arbitration and disclosure obligations under domestic law.
\end{abstract}

Keywords: TPF, Third Party Funding, disclosure.

\section{INTRODUCCIÓN}

Muchos juristas y especialistas urgen incluir en las reglas de los centros de arbitraje que aún no lo han hecho, normas que promuevan la transparencia de los laudos arbitrales, regulando su publicidad. Otro gran sector de ellos no deja de recordar que entre las razones más importantes por las que las partes acuden al arbitraje se encuentran diversos motivos de estricta confidencialidad, por lo que ellas no desean que se divulguen los pormenores de su controversia y sus resultados.

Algunos autores, al analizar la naturaleza jurídica de los laudos arbitrales observan que hay dos teorías respecto a la naturaleza del arbitraje como tal: la teoría contractualista y la 
teoría jurisdiccional ${ }^{1}$. Para los defensores de la primera teoría con base en la autonomía de la voluntad, y al origen contractual del arbitraje, habría un deber de confidencialidad de todo el proceso arbitral, abarcando incluso al laudo, sea cuando según la normativa aplicable la confidencialidad es la regla o cuando, requiriéndose estipulación expresa, las partes han acordado la confidencialidad del arbitraje. Por otro lado, si se atiende a los defensores de la teoría jurisdiccional, los laudos se someterían a las mismas reglas de publicidad de las sentencias expedidas por órganos jurisdiccionales.

Los centros arbitrales paulatinamente van aportando precisión y detalle para mejorar los atractivos del mecanismo para los usuarios y dotarlo de la mayor fiabilidad. Ciertamente, los centros de arbitraje han sido motores de innovaciones en materia de transparencia, lo cual es muy entendible porque son los principales actores en las políticas de los sistemas de arbitraje nacional e internacional. Pero también atienden las razones de las partes que pactan en el convenio arbitral la confidencialidad del arbitraje.

Inmediatamente, el presente artículo abordará la institución de la confidencialidad en el arbitraje comercial en la doctrina y en la ley ecuatoriana y se referirá a distintos puntos de vista y posiciones sobre publicidad y confidencialidad en algunos países y centros arbitrales del mundo. Continuaremos resaltando algunos fundamentos en pro y en contra para la publicación de los laudos. En las conclusiones se pretende compatibilizar las distintas posiciones y configurar lineamientos concretos que tiendan a la publicidad de los laudos sin afectar la confidencialidad.

\section{Confidencialidad}

Como más adelante se verá, las normas sobre confidencialidad difieren en las distintas legislaciones por lo que es importante tomar en cuenta a la correspondiente ley de arbitraje, así como a los reglamentos de la corte de la cual se trate.

1. V. Espinoza et al., "El fin del paradigma de la confidencialidad: Hacia la Publicidad de los Laudos Arbitrales", Semillero de Derecho Procesal, Facultad de Derecho Universidad de Chile. 


\subsection{Distintas categorías de leyes y sistemas}

Siguiendo a Jiménez Blanco, que cita a Caivano, se pueden distinguir tres categorías de leyes: a) aquellas que no contienen siquiera una mera mención de la confidencialidad, b) aquellas que apenas enuncian un principio general, aunque sin mayor regulación, c) aquellas que, con matices, avanzan en una reglamentación que pretende abarcar, al menos, los supuestos más usuales².

Dentro de la primera categoría ubica a la Ley Modelo de arbitraje comercial internacional de UNCITRAL, así como las legislaciones sobre arbitraje de Alemania, Arabia Saudita, Argentina, Austria, Bélgica, Botswana, Bulgaria, Canadá, Chile, Colombia, Corea, Dinamarca, Egipto, Estados Unidos de Norteamérica, Gran Bretaña, Guatemala, Holanda, Honduras, Italia, Japón, México, Panamá, Paraguay, Portugal, Suecia, Suiza, Túnez, Uganda y Uruguay, entre otras.

En la segunda, sitúa a aquellas que, si bien se refieren a la confidencialidad, no avanzan más que en enunciados más o menos genéricos o regulaciones fragmentarias, pero carecen de un régimen que permita discernir claramente cuál es el alcance objetivo del deber de confidencialidad ratione materiae (qué aspectos del arbitraje son confidenciales) y obligados a mantener la confidencialidad). Ejemplos de esta categoría son las legislaciones de Bolivia, Brasil, España, Francia y Venezuela. Claros exponentes de la tercera categoría son a su juicio las nuevas legislaciones de Nueva Zelanda, Perú, Escocia y Australia que, aun con lagunas, contienen un mayor grado de precisión en relación con el alcance del deber de confidencialidad.

En el Perú, donde la confidencialidad del laudo es la regla general, se generan excepciones como la consagrada en el artículo 14.1 del Reglamento de Arbitraje del Centro de Conciliación y Arbitraje Nacional e Internacional de la Cámara de Comercio de Lima que establece que existen situaciones en la que es necesario hacer públicos los laudos "por exigencia legal, para proteger o

2. G. JimÉnEz Blanco. Confidencialidad en el Arbitraje. Revista de Arbitraje Comercial e Inversiones. Vol. VIII, No. 3, 2015. pp. 735-748. 
hacer cumplir un derecho o para interponer el recurso de anulación o ejecutar el laudo arbitral ante el Poder Judicial" ${ }^{3}$.

En el mismo país, según señala Serván, tanto la CCL (Cámara de Comercio de Lima) como Amcham contemplan la publicación de laudos comerciales. Sin embargo, solamente la CCL publica laudos comerciales con fines académicos, siempre que ninguna parte objete la publicación" ${ }^{4}$. Además, a esta tercera categoría habría que agregar el reglamento de la Corte de Arbitraje Internacional de Londres (LCIA) 5

Desde otra perspectiva, conforme el análisis efectuado por el Semillero de la Facultad de Derecho de la Universidad de Chile, "en el caso de la regulación comparada, la configuración de la confidencialidad no es uniforme, ya que, a partir de los ordenamientos analizados, se pueden distinguir sistemas en los que se concibe como un elemento esencial de la institución, como Francia, España, Costa Rica y Perú; aquellos en los que se entiende que debe ser pactado por las partes en forma expresa, como Noruega, Nueva Zelanda y Ecuador; otros en los que simplemente no hay legislación expresa al respecto, como Estados Unidos y Brasil; e, incluso, situaciones que reniegan completamente de la confidencialidad, consagrando la publicidad de los procesos, como Colombia" 6 .

\subsection{El caso de Ecuador}

Efectivamente, la legislación ecuatoriana reconoce la confidencialidad del arbitraje cuando las partes así lo pacten en el convenio arbitral, por lo que se ubicaría en el segundo de los mencionados sistemas. El Art. 34 de la Ley de Arbitraje y Mediación señala:

Art. 34.- Las partes sin perjuicio de los derechos de terceros, podrán convenir en la confidencialidad del procedimiento

3. Universidad Externado de Colombia. Facultad de Derecho. Blog de Derecho de los Negocios, 2016. <https://bit.ly/3DRszHo>

4. N. Serván Eyzaguirre. Armonizando tensiones: La necesidad de transparencia en el arbitraje sin destruir la confidencialidad. Forseti Revista de Derecho. Vol. 8, No.12, 2020, pp. 48-68.

5. Universidad Externado de Colombia. N. 3.

6. G. Jiménez Blanco. N. 1. 
arbitral, en este caso podrán entregarse copias de lo actuado solamente a las partes, sus abogados o al juez que conozca el recurso de nulidad $\mathrm{u}$ otro recurso al que las partes se hayan sometido." No se puede dejar de observar que en buena medida cuando se someten a arbitraje, las partes acuerdan convenir la confidencialidad del arbitraje comercial. Usualmente, las cláusulas modelo preparadas por los Centros de Arbitraje del país incluyen la cláusula de confidencialidad, con gran aceptación de los usuarios.

Puede decirse que en Ecuador la confidencialidad no siempre es inherente al proceso arbitral puesto que requiere el acuerdo expreso de las partes, y, además, si por cualquier razón terceros se vieren afectados e involucrados en el arbitraje, para ellos no regiría la confidencialidad pactada.

Se ha dicho generalmente que una de las razones por las que las partes prefieren acudir al arbitraje, en Ecuador y otros países, es por la confidencialidad de la controversia, que impide que se divulgue total o parcialmente, detalles del litigio entre ellas y sus resultados. La confidencialidad reduce los riesgos de que se conozca por parte de terceros información y datos sensibles para las partes como secretos comerciales y temas de propiedad intelectual. Para muchos usuarios ello constituye una gran ventaja del arbitraje. Se dice también que países y centros de arbitraje que defienden la confidencialidad reciben más casos de arbitraje que los que no lo hacen.

Igualmente, según encuestas efectuadas en el exterior por Queen Mary University y White $\mathcal{E}$ Case, las partes tienen preferencia por la confidencialidad en el arbitraje comercial, la consideran importante o muy importante y además, es una de las características que más valora en el arbitraje internacional.

No debe dejar de observarse que otra razón para preferir ir al arbitraje antes que a la justicia ordinaria es la celeridad del proceso arbitral frente a la lentitud de procedimientos de los juzgados ordinarios. También la honestidad con la que se manejan los procesos en los principales centros de arbitraje es otro factor importante para esta inclinación de los usuarios. 


\subsection{La teoría de que la confidencialidad es inherente al arbitraje}

Cabe mencionar que, a nivel internacional durante muchos años, la posición clásica ha considerado a la confidencialidad como un elemento natural o implícito del convenio arbitral y del arbitraje. Por ejemplo, la Corte de Apelaciones de Inglaterra en el caso Ali Shipping Corporation v Shipyard Trogir señaló que "como cuestión de principio la obligación de confidencialidad (cualesquiera que sean sus límites precisos) surge como corolario esencial de la privacidad de los procedimientos de arbitraje". La Corte propuso el término "que surge de la naturaleza que el propio contrato requiere implícitamente"7.

Jiménez Blanco refiere que, según J. F. Merino Merchán, el fundamento de este principio se encuentra en la naturaleza misma del arbitraje en general ya que, históricamente, como la mayoría de esas soluciones extrajudiciales han aflorado en el seno de una concepción nítidamente privatista en la que la privacidad ha ocupado un lugar central, y que el propio Merino Merchán insiste en que la confidencialidad es un elemento casi configurador de la institución arbitral aunque el reconocimiento legal no ha sido ni tan categórico y tan universal como podría esperarse ${ }^{8}$.

\section{4 Extensión de la confidencialidad}

La citada publicación de la Universidad Externado de Colombia comparte la posición del tratadista Jiménez Blanco, al considerar que el objeto de la confidencialidad del arbitraje se extiende a:

"La existencia misma del arbitraje y, en consecuencia, los datos concernientes a los detalles de la disputa: las partes, las acciones ejercidas, las peticiones de las partes, la existencia de reconvención, la composición del tribunal arbitral, la identidad de los abogados, de los testigos y peritos.

Los documentos que puedan obrar en el arbitraje (los escritos de las partes, las decisiones del tribunal, los documentos aportados por las partes, los informes periciales o cualesquiera otras pruebas);

7. N. Serván Eyzaguirre. N. 4.

8. G. Jiménez Blanco. N. 1. p. 737. 
Las audiencias de celebración de prueba y en su caso de conclusiones;

Las deliberaciones del tribunal arbitral;

El laudo, hasta su comunicación a las partes y respecto de terceros, más allá de esa comunicación a las partes. Anotando que determinados laudos pueden resultar publicados conforme a su normativa aplicable" ${ }^{\prime \prime}$.

La confidencialidad también tiene sus excepciones naturales, por ejemplo, en situaciones donde el laudo es sometido a conocimiento de tribunales estatales para ejecución, anulación o incluso en una etapa previa con las medidas cautelares ¿Se conserva la confidencialidad en estos casos? ¿Debe preponderar la publicidad de las actuaciones judiciales? La publicación destaca que no existen actuaciones judiciales secretas y que al acudir a la jurisdicción ordinaria están renunciando de algún modo a la confidencialidad.

\section{Normas de Algunos países y CENTROS De ARbitraje SOBRE LA PUBLICIDAD DE LOS LAUDOS}

En una nueva orientación del tema de la confidencialidad, ciertos tratadistas y centros de arbitraje han impulsado la tendencia de la publicidad del laudo bajo ciertas condiciones y matices. Incluso en países donde la confidencialidad es la regla general, o en los que no existe norma expresa, la tendencia es introducir o reconocer ciertas limitaciones a la confidencialidad, generalmente sin afectar este principio.

Sin duda alguna, siguiendo la indicada publicación, de las aristas más importantes en el tema ha sido la confidencialidad de los laudos, en el cual también encontramos cuatro escenarios ${ }^{10}$ :

a. La confidencialidad de los laudos como regla general. Por ejemplo, el reglamento de la Corte de Arbitraje Internacional de Londres (LCIA) que en el artículo 30.1 expresa que "las partes se

9. Universidad Externado de Colombia. N. 3.

10. Ídem. 
comprometen como principio general a mantener la confidencialidad de los laudos en el arbitraje (...)".

b. No existe disposición expresa. Por ejemplo, el reglamento de la Comisión Económica y de Arbitraje Comercial de China (CIETAC), que si bien presume la confidencialidad de las audiencias no regula nada respecto a la publicación del laudo.

c. Publicidad del laudo con el consentimiento expreso de las partes. Como el reglamento CNUDMI. y el reglamento del Centro Internacional de Arreglo de Diferencias Relativas a Inversiones (CIADI) artículo 48.5 donde se establece que “El Centro no publicará el laudo sin consentimiento de las partes".

d. Por último, donde el laudo se entiende público a menos que las partes manifiesten lo contrario. Como, por ejemplo, el reglamento de arbitraje de la Bolsa de fletes del Japón (JSE) donde menciona en la sección 26 que el laudo puede ser publicado a menos que las partes comuniquen con anterioridad su objeción.

Anota también la misma publicación que según encuesta efectuada, los asuntos que se deben mantener de manera confidencial son los siguientes: con $69 \%$ el laudo completo y $58 \%$ los detalles del laudo que permitan la identificación de las partes.

A continuación, una referencia resumida de la forma en que el tema de la publicidad se encuentra regulado en los convenios y reglamentos que rigen los principales centros e instituciones de arbitraje:

a. La Comisión de las Naciones Unidas para el Derecho Mercantil Internacional (CNUDMI) en su Art. 34 del Reglamento señala que "Podrá hacerse público el laudo con el consentimiento de las partes o cuando una parte tenga la obligación jurídica de darlo a conocer para proteger o ejercer un derecho, y en la medida en que así sea, o con motivo de un procedimiento legal ante un tribunal $u$ otra autoridad competente"11.

b. La Cámara Internacional de Comercio o ICC por sus siglas en inglés, en su nota dirigida a las Partes y al Tribunal Arbitral sobre

11. Reglamento de Arbitraje de la CNUDMI. Art. 34, numeral 5. 
la Conducción del Arbitraje de Conformidad con su Reglamento de Arbitraje, establece que:

La Secretaría informará a las partes y los árbitros, en el momento de la notificación de cualquier laudo final dictado desde el 1 de enero de 2019, que dicho laudo final, así como cualquier otro laudo y opiniones disidentes o coincidentes emitidas en el marco del procedimiento, pueden publicarse íntegramente transcurridos al menos dos años de la fecha de dicha notificación.

Las partes podrán acordar un plazo mayor o menor para la publicación.

En cualquier momento antes de la publicación, cualquiera de las partes podrá oponerse a la publicación o exigir que la totalidad o parte del texto de un laudo se anonimice o se utilicen seudónimos, en cuyo caso el laudo no será publicado o se anonimizará o se utilizarán seudónimos en la totalidad o parte de su texto.

En caso de que exista un acuerdo de confidencialidad que cubra ciertos aspectos del arbitraje o del laudo, la publicación estará sujeta al consentimiento específico de las partes.

La Secretaría podrá anonimizar o utilizar seudónimos con respecto a los datos personales incluidos en el laudo según resulte necesario conforme a los reglamentos de protección de datos aplicables.

La Secretaría podrá, siempre que lo decida, no proceder con la publicación de un laudo. ${ }^{12}$

Además, el Apéndice II del Reglamento de Arbitraje de la CCI en su Art. 1 dispone que: "El Presidente o el Secretario General de la Corte podrán autorizar que se den a conocer a investigadores que efectúen trabajos de naturaleza académica los laudos y otros documentos de interés general, salvo memoriales, notas,

12. Nota a las partes y al Tribunal Arbitral sobre la conducción del Arbitraje de conformidad con el Reglamento de Arbitraje de la CCI. Sección III, Tribunal Arbitral, D. Publicación de laudos, 1 de enero de 2019. 
manifestaciones y documentos presentados por las partes dentro del marco de un procedimiento arbitral. ${ }^{13 \prime \prime}$

c. En la Corte Internacional de Arbitraje de Londres, los numerales 1 y 3 del artículo 30 sobre Confidencialidad de su Reglamento disponen que:

Las partes se comprometen, como principio general, a mantener la confidencialidad de todos los laudos arbitrales, así como de todos los materiales del arbitraj e creados a efectos del mismo y de todos los demás documentos producidos por otra parte en el procedimiento que no sean de dominio público, salvo y en la medida en que su revelación pueda ser exigida a una parte por obligación legal, para proteger o perseguir un derecho legal, o para ejecutar o impugnar un laudo en un procedimiento legal ante un tribunal estatal $u$ otra autoridad legal [...]

La LCIA no publicará ningún laudo o parte del mismo sin el previo consentimiento por escrito de todas las partes y del Tribunal Arbitral ${ }^{14}$.

d. Por la trascendencia que tiene en las inversiones, hay que referirse a las normas relativas a la publicidad de laudos del Convenio del Centro Internacional de Arreglo de Diferencias Relativas a Inversiones (el CIADI). El Artículo 48 del Convenio del CIADI determina que: (5) “El Centro no publicará el laudo sin consentimiento de las partes", lo cual se reafirma en Regla 48 de las Reglas de Arbitraje que dice (4) "El Centro no publicará el laudo sin el consentimiento de las partes. Sin embargo, el Centro deberá incluir prontamente en sus publicaciones extractos del razonamiento jurídico del Tribunal"15.

e. Acuerdo de la Asociación Transpacífico, (TPP por sus siglas en inglés: TransPacific Partnership. Se afirma que el TPP es el tratado comercial más ambicioso de la historia de la humanidad. El art. 9.19.4, entrega a los inversionistas la opción de elegir diferentes foros para substanciar el arbitraje, en particular, los siguientes: i) el

13. Reglamento de Arbitraje de la CCI. Apéndice II, Art. 1, numeral 4.

14. Reglamento de la Corte de Arbitraje Internacional de Londres. Art. 30, 1 de enero de 1998.

15. Centro Internacional de Arreglo de Diferencias Relativas a Inversiones. Reglamento de Arbitraje, Art. 48. 
CIADI y las Reglas Procesales Aplicables a los Procedimientos de Arbitraje del CIADI; ii) las Reglas del Mecanismo Complementario del CIADI; iii) las Reglas de Arbitraje de la CNUDMI o; iv) tras un acuerdo entre las partes, la designación de cualquier otra institución arbitral o cualesquiera otras reglas de arbitraje ${ }^{16}$.

f. Las normas de otros Centros de Arbitraje. Serván Eyzaguirre en el artículo ya comentado, señala que las del brazo internacional de la American Arbitration Association (ICDR), las del Singapore International Arbitration Centre (SIAC) y las de Hong Kong International Arbitration Centre (HKIAC), y refiere que tanto la ICDR y HKIAC tienen provisiones para la publicación de laudos arbitrales ${ }^{17}$. Las reglas del SIAC establecen que sí se puede publicar los laudos siempre y cuando se suprima el nombre de las partes y exista el consentimiento de estas y el tribunal arbitral. El HKIAC publicará laudos una vez que haya borrado cualquier dato que permita identificar a una de las partes. Finalmente, ICDR solamente publicará los laudos cuando exista consentimiento expreso entre las partes o la ley lo requiera. El Reglamento de Arbitraje Suizo, en vigor desde el 1 de enero de 2004, contiene una disposición general sobre la confidencialidad en los laudos y resoluciones, a más de en otras actuaciones arbitrales. Los laudos o una orden, íntegramente o por extractos. solo podrán ser publicados cuando que se reciba una solicitud, todas las referencias a nombres de las partes sean suprimidas y ninguna de las partes se oponga a la publicación.

Nos encontramos frente a distintos estándares; sin embargo, en cualquier caso, la objeción de cualquiera de las partes impedirá la publicación del laudo. Esta es una clara muestra de los balances entre confidencialidad y transparencia ${ }^{18}$.

Además, siguiendo al tratadista J.F. Merino, de la misma forma el Reglamento de la Organización Mundial de la Propiedad Intelectual (OMPI), recoge, y establece entre las partes un deber de confidencialidad respecto al laudo; en cuya virtud solo podrá divulgarse este a terceros cuando expresamente lo autoricen

16. Transpacific Partnership. Capítulo 9, Art. 9, numeral 19.4.

17. N. Serván Eyzaguirre. N. 4.

18. Idem, p. 65. 
las partes o se trate de un asunto de dominio público o sirva la divulgación para proteger los derechos jurídicos de una parte ${ }^{19}$.

El Semillero de la Facultad de Derecho de la Universidad de Chile ${ }^{20}$ destaca que "en aquellos casos llevados a cabo por organizaciones y centros de arbitrajes es posible encontrar una política interna de accesibilidad a sus fallos, pero dicha política de selección de laudos no es de conocimiento público". Este es el caso del CAM Santiago, organización que en su página web expone: “El CAM Santiago presenta a la comunidad jurídica y empresarial una selección de las sentencias arbitrales dictadas por árbitros del Centro desde 1994 hasta la actualidad.

La publicación de las sentencias arbitrales on line constituye un elocuente testimonio del desarrollo del arbitraje institucional en nuestro país y permite dimensionar el creciente posicionamiento de los métodos alternativos de solución de controversias a nivel nacional"21. Luego aclara que "para salvaguardar la confidencialidad de los arbitrajes, todas las sentencias fueron sometidas a un proceso de edición para dejar en anonimato a las partes y los terceros involucrados" ${ }^{\prime 22}$.

\section{JURISPRUDENCIA INTERNACIONAL CON RELACIÓN A LA PUBLICIDAD DE LOS LAUDOS}

El tratadista Endara Flores, en relación con el tema de la publicidad de los laudos, incluye un pronunciamiento de un tribunal de arbitraje estadounidense bajo normas UNCITRAL que señala que en el Caso Hassneh Insureance c. Mew resolvió que:

el laudo y los motivos expuestos en dicho laudo eran de naturaleza distinta de los demás elementos del proceso arbitral (por ejemplo, notas, y transcripciones de la prueba, declaraciones testimoniales, presentaciones y escritos, todos los cuales... están protegidos... por el principio de privacidad que deriva del hecho de la audiencia sea a puertas cerradas ${ }^{23}$.

19. J. F. Merino Merchán. "Confidencialidad y Arbitraje". Spain arbitration review: Revista del Club Español del Arbitraje, №. 2, 2008, p. 25.

20. G.JiméNEZ BlANCO. N. 1.

21. Ídem.

22. Ídem.

23. F. Endara Flores. La Confidencialidad en el Arbitraje. El caso de Ecuador. Revista CREA. Universidad Católica de Temuco. Pág.36. 
Por otro lado, determinó que el laudo "era potencialmente un documento público a los efectos de su supervisión o ejecución por parte de los tribunales, pudiéndose divulgar sin consentimiento de la otra parte o autorización del tribunal si y solamente si, la parte que así lo solicitaba necesitaba proceder para hacer valer un derecho personal o protegerlo frente a un tercero". Sobre este punto podemos concluir que "los arbitrajes... son procedimientos privados que no producen ningún documento para el conocimiento público... a pesar de esto la misma lógica no se puede aplicar a un laudo. Un laudo tal vez tenga que ser puesto en conocimiento público por temas $u$ asuntos contables o para ejecutar los derechos que ese laudo determinón ${ }^{24}$.

Cierta jurisprudencia referente a arbitrajes comerciales y de inversiones internacionales en los que es parte el propio Estado o una entidad del sector público se promueve la publicidad de los laudos debido a que aquellos no pueden ser inmunes a la transparencia pública.

J. F. Merino Merchán señala que "en el caso Esso Australia Resoruces c. Honourable Sidney James Powman, la conclusión del tribunal australiano fue que, dado que en el arbitraje intervenía el Estado australiano, la confidencialidad no podía considerarse un atributo fundamental y que debía prevalecer el interés legítimo del público en obtener información relativa a los asuntos de las autoridades públicas" 25 . También refiere a que a casi idéntica solución se llegó en los casos de Cockatoo Dockyard, en el que se planteó la incompatibilidad de exigir un "alto nivel de confidencialidad" con el "derecho a saber del público", dado el evidente interés público que encerraba el laudo recaído en ese arbitraje, realizado de acuerdo con el Tratado de Libre Comercio de América del Norte (TLCAN); y el caso $A M C O$ c. República de Indonesia, aunque en este último arbitraje las reglas que se siguieron fueron las del Centro Internacional de Arreglo de Diferencias Relativas a Inversiones (CIADI) ${ }^{26}$.

El mismo autor en el artículo ya indicado, refiere que el control jurisdiccional de los laudos, de una parte y la revelación pública de los datos suministrados en los arbitrajes comerciales e internacionales

24. Ídem.

25. J. F. Merino Merchán. N. 13, p. 24.

26. Ídem. 
en los que es parte el Estado o un organismo público dependiente del mismo, ha hecho que por vía de Internet y otros medios se haya dado una publicidad urbis et orbe a esos arbitrajes; "creando una crisis sin precedentes en la confidencialidad de la institución arbitral" $^{\prime 27}$. Por tal motivo, y para preservar la confidencialidad como elemento configurador del arbitraje, algunos reglamentos han sido modificados con el único propósito de imponer a las partes un deber de confidencialidad.

\section{RAZONES A FAVOR Y EN CONTRA DE LA PUBLICACIÓN DE LOS LAUDOS ARBITRALES}

Un amplio debate generado en foros especializados locales e internacionales conducen a cimentar la idea de que para que prime la trasparencia es necesario la publicidad de los laudos arbitrales, agregando en muchos casos fundamentos de diversos órdenes, que más adelante los expondremos brevemente.

Uno de ellos es la necesidad de contar con precedentes disponibles para árbitros y abogados que permitan analizar y resolver litigios arbitrales con base a otros fallos en asuntos similares. Un tratadista señala que "el potencial precedente de los laudos arbitrales constituye un bien público. Aunque los laudos no están sujetos a un sistema formal de stare decisis, las decisiones de los tribunales arbitrales pueden aportar una contribución sustancial e importante a la jurisprudencia comercial, orientando a los futuros tribunales y a los tribunales nacionales cuando se les planteen controversias similares" ${ }^{28}$. También Serván dice, citando a Born, que "su publicación puede generar beneficios de eficiencia, coherencia y previsibilidad, ya que las decisiones previas pueden orientar a los tribunales posteriores" ${ }^{\prime 2}$.

No son pocos los que destacan que cuando hay un interés público, como puede ser la intervención del Estado o una de sus entidades como parte en un arbitraje debe reconocerse la publicidad de los laudos.

27. Ídem.

28. N. Servan Eyzaguirre. N. 4, p. 65.

29. Ídem. 
En muchos casos, para cumplir con las exigencias de los usuarios del mecanismo, los centros arbitrales se han convertido en impulsores de cambios que perfeccionen el sistema arbitral, generando más confianza del público y profesionales del derecho. Las mejoras al sistema que contribuyan a la seguridad jurídica y transparencia como sería la publicidad de los laudos robustecen el mecanismo.

Más aún, el mismo autor señala que los centros arbitrales tienen clara esta situación y cita una prestigiosa publicación que menciona: "para ser percibidas como legítimas, justas desde el punto de vista del procedimiento y dignas de confianza, las instituciones de arbitraje deben exhibir el máximo nivel de transparencia permitido por sus normas. Los procesos de la institución deben ser, y ser percibidos como tales, disciplinados y basados en reglas, y reflejar una ética de independencia, responsabilidad y profesionalidad" ${ }^{30}$.

Cabe destacar que la falta de visibilidad de los laudos restringe también el conocimiento jurídico, cuestión que muchas veces se ve como accesoria. Sin embargo, el trabajo de análisis, crítica o sistematización realizado por la doctrina en sus documentos sirven para una interpretación cada vez más clara de la ley, y para el estudio minucioso de aquellos fallos que son célebres dentro de la cultura jurídica.

Siguiendo a los especialistas de Galicia Abogados de México, autores de Publicidad de Laudos Arbitrales en el Arbitraje Comercial: Ordenando la Discusión ${ }^{31}$, enunciaremos las principales razones que ellos acertadamente señalan como postulados a favor de la publicación de los laudos arbitrales.

a. desarrollo del Derecho (costumbre y práctica). Con independencia del derecho sustantivo de un país específico que, en la mayoría de los casos aplican los tribunales arbitrales, los tribunales crean un corpus iuris propio sobre el procedimiento y en algunos casos sobre la interpretación de ciertas prácticas comerciales. En el arbitraje internacional se ha identificado que los tribunales citan

30. Ídem, p. 63.

31. Especialistas de Galicia Abogados. Publicidad de Laudos Arbitrales en el Arbitraje Comercial: Ordenando la Discusión. Themis. Revista de Derecho 77. Enero-junio 2020. 
en sus laudos a otras resoluciones, por lo que la publicidad de los laudos ayudaría a crear una teoría del precedente sólida.

b. certidumbre y seguridad jurídica. Se trata de una certidumbre dentro de las prácticas comerciales y su interpretación constante y evolutiva por parte de los tribunales arbitrales, así como de reglas procesales y jurisdiccionales y también con relación a las decisiones arbitrales. Esto llevaría al estudio de casos, para procurar prever las posibilidades de éxito en los reclamos en un juicio arbitral.

c. consistencia. La publicidad de los laudos, así como la propagación de la cultura jurídica del precedente llevaría a que las reglas se apliquen de una manera más uniforme y a gestar principios jurídicos.

d. educación y aprendizaje (creación de doctrina). El arbitraje comercial se acerca y se asemeja cada vez más a los sistemas de precedentes. Con la publicación de los laudos se lograría tener un repertorio mucho más amplio para el estudio de este mecanismo de solución de controversias.

e. calidad de laudos. La publicidad de los laudos llevaría sin duda a un mayor cuidado de los árbitros en la redacción de los mismos, y les incentivaría a un mejor desarrollo de las resoluciones.

f. desmonopolización y legitimidad. Entre mayor visibilidad tenga la labor de los árbitros, más se verá robustecida la legitimidad del sistema arbitral y permitiría que un mayor número de personas lo entendieran como un mecanismo de solución de controversias accesible y viable y no como un sistema lejano, oscuro y confuso.

g. equidad procesal entre jugadores primerizos y jugadores recurrentes. La publicación de laudos arbitrales ayudaría a nivelar el acceso al arbitraje para partes no experimentadas. Propiciaría que los árbitros creen reputaciones públicas que vayan más allá de lo conocido en el gremio y que permita a cualquier parte obtener más información sobre sus perfiles al momento de tomar una decisión sobre su elección. Asimismo, permitiría que árbitros más jóvenes, y sin tanta reputación gremial, logren hacerse de una imagen pública que les permita su inserción a mayores arbitrajes y así, se abonaría a una práctica más inclusiva y plural. 
h. transparencia y anticorrupción. Se ha considerado que la transparencia y los esfuerzos anticorrupción tienen una relación muy estrecha e indisoluble. La publicidad de los laudos serviría un papel social de divulgación de casos de corrupción y pondría a prueba a los tribunales arbitrales en los esfuerzos en esta lucha. Por otro lado, al ser públicas las decisiones de los árbitros, estas serían más evidentes y en caso de que se emitieran sin fundamento con señales de arbitrariedad, estos enfrentarían no solo consecuencias legales por eventuales juicios de nulidad, sino también que su reputación estaría en juego.

A continuación, los contrapesos que los mismos autores identifican frente a los beneficios arriba enunciados para la publicación de los laudos arbitrales.

a. la vulneración de los derechos de protección de datos personales o confidenciales o secretos comerciales. Frente a esta crítica, como medida de mitigación, algunas instituciones han optado por publicar laudos en formatos de extracto, resumidos, revisados o anonimizados.

b. el encarecimiento del procedimiento arbitral y demoras. La crítica consiste en que la publicidad de los laudos demandaría más tiempo de los árbitros en los análisis y razonamientos ya que los laudos podrían generar un precedente, y conllevar un incremento de tiempo y honorarios de los árbitros. Asimismo, podría aumentar los costos de arbitraje por preparación de extractos, resúmenes o versiones anonimizadas de los laudos.

c. la imposibilidad de crear una verdadera doctrina arbitral comercial. A diferencia del arbitraje de inversión, en el arbitraje comercial las decisiones sobre el fondo de la disputa no prometen causar un impacto importante en la comunidad arbitral, pues los árbitros (no necesariamente expertos en la ley aplicable) son quienes interpretan las circunstancias del caso considerando la ley aplicable, así como la información proporcionada por las partes y expertos. A manera de ejemplo, en el análisis y razonamiento del fondo de un caso, la interpretación de la legislación mexicana realizada por un árbitro de nacionalidad distinta no forzosamente sería seguida por un árbitro mexicano. 
d. el aumento de conflictos de interés y de recusaciones de árbitros. Una de las principales causales de recusación es que los árbitros hayan tomado una posición pública con relación a algún aspecto del arbitraje, mediante cualquier forma. En este planteamiento se teme que de ser implementada la publicidad de los laudos arbitrales comerciales las posiciones de los árbitros sobre ciertos aspectos serían públicas. Podría darse que alguien argumente que aumentaría el número de revelaciones que deben efectuar los árbitros al respecto y naturalmente de ser así se incrementaría el número de recusaciones.

e. el double-hatting frente a la publicidad de los laudos. Se refiere a la posibilidad de que los abogados actúen como árbitro en un caso y como representante de parte en otro. Cuando los abogados actúen como árbitros pueden estar tentados a resolver un caso en la forma que analizó como representante de parte. Además, la confusión de roles podría ocasionar que el árbitro tenga la tentación de emitir laudos que puedan ser usados como precedente en un caso en que actúa como representante de parte. También podría ser según esta apreciación que los árbitros se vean influenciados en su voto por el hecho de que el laudo sea público. Vistas estas posibilidades la publicidad de laudos arbitrales podría conllevar un aumento de conflictos de interés y confusión de roles.

\section{Conclusiones}

La publicación de los laudos arbitrales tiene aristas y múltiples aspectos que deben ser cuidadosamente evaluados y analizados. En nuestro medio, ha primado la cláusula de confidencialidad en los convenios arbitrales, debido a una clara preferencia de los usuarios por este mecanismo. No obstante, también hay una sólida tendencia que promueve la transparencia del proceso arbitral, y se advierte que no pocos consideran que un elemento clave para ello es la publicidad de los laudos.

De un análisis de los planteamientos a favor y en contra de la publicación que hemos sintetizado, nos parece que los beneficios de la publicidad de los laudos son mayores que los argumentos en contra, sin perder de vista la voluntad de las partes sobre confidencialidad que pudiere constar en el convenio arbitral. 
También, creemos que es posible acercarse a un justo intermedio, que, respetando el convenio de confidencialidad, permita a los centros la publicidad de los laudos que no han sido impugnados, esto es, los laudos sobre los que no se haya presentado una acción de nulidad según la Ley de Arbitraje y Mediación.

Para ello se puede tomar como guía ciertas condiciones para la publicidad que adoptan los centros de arbitraje y mediación internacionales más reconocidos. Nos parece interesante estudiar la publicidad de los laudos anonimizando los datos de las partes, en forma similar a lo que al respecto disponen las reglas de la ICC. Ello daría más tranquilidad a las partes en cuanto a que no se divulgarán los datos del laudo y su controversia con relación a nombres de personas, partes o información sensible.

En todo caso, hay que tener en cuenta que cualquiera de las partes que hubiere pactado un arbitraje confidencial podría oponerse a la publicación. Parece difícil la publicación de un laudo si las partes no consienten en ello. También como alternativa podría contemplarse la publicación de extractos o resúmenes de los laudos igualmente anonimizados. Puede, además, regularse la entrega o divulgación de laudos restringida o limitada con fines académicos o para el estudio de tribunales arbitrales con casos similares.

La publicidad de los laudos de los procesos arbitrales originados en convenios en los que no se hubiere pactado confidencialidad, no tendría limitación en lo que se refiere a la expresión de la voluntad de las partes, pero creemos conveniente que los centros de arbitraje sean igualmente cautelosos y consideren la anonimización de datos. Por otro lado, no hay que perder de vista que las acciones de nulidad conllevan una limitación a la confidencialidad en razón de que tiene que remitirse el laudo a la autoridad pertinente.

Difícilmente se podría admitir que sin una reforma a la ley puedan publicarse los laudos arbitrales por parte de los centros de arbitraje, sin previo consentimiento de quienes han estipulado la confidencialidad en el convenio arbitral. Pero los convenios arbitrales podrían contener limitaciones voluntarias a la confidencialidad, como, por ejemplo, la publicidad de los laudos anonimizados o con exclusión de información sensible, y de resúmenes o extractos. 
Para resolver sobre el tema, los centros de arbitraje deben cuidar que se cumpla el principio de la autonomía de la voluntad de las partes y al mismo tiempo actuar con iniciativas que lleven al mejoramiento del sistema arbitral y su transparencia. 



\section{CABEZAS \\ WRAY \\ ¿ ALBÁN}

Nuestros resultados son producto de la experiencia, integridad, preparación y creatividad. 



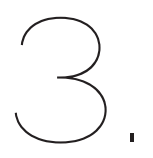

Ensayos libres 
